\title{
GOOD KILL: GUERRA PÓS-HEROICA E PSICOPATOLOGIA DO DRONE
}

\author{
GOOD KILL: POST WAR HEROIC AND PSYCHOPATHOLOGY OF THE DRONE
}

Rafael Leopoldo*

\section{RESUMO}

Este presente artigo visa fazer uma análise do filme Good Kill, do diretor Andrew Niccol. Porém, leva-se em conta o desenvolvimento filosófico da ideia de vigilância perpassando três autores. Com o primeiro autor analisaremos a leitura de Michel Foucault da obra "O Panóptico" de Jeremy Bentham, assim, caracterizando as sociedades disciplinares com a vigilância dos ambientes fechados. Com o segundo autor, Gilles Deleuze, prosseguiremos para a análise das sociedades de controle e a concepção de um controle a céu aberto. Por último, nos voltamos à Grégoire Chamayou, e a concepção de uma vigilância geoespacial via drones. Daí o filme Good Kill se mostrar como um exemplo viável para uma apreciação desta última forma de vigilância como, também, remontar a uma psicopatologia do drone.

PALAVRA-CHAVE: good kill. Sociedade disciplinar. Sociedade de controle. Drones.

\section{ABSTRACT}

This present article aims to analyze the movie Good Kill, by Andrew Niccol. However, it takes into account the philosophical development of surveillance idea permeating three authors. With the first author, we analyze Michel Foucault`s reading of the work "Panopticon", by Jeremy Bentham, as a result of it we describe the disciplinary societies with surveillance of indoor spaces. With the second author, Gilles Deleuze, we will proceed to the analysis of control society and understand the control in open spaces. Finally, we turn to Grégoire Chamayou, and his conception of geospatial surveillance via drones. From now, the film Good kill show as a viable example to an appreciation of the last form of surveillance, as also mark a possible psychopathology of drone.

KEYWORD: Good kill. Disciplinary societies. Control society. Drones.

\footnotetext{
* Mestre em psicologia pela Universidade Federal de Juiz de Fora (UFJF). Pós-graduado pela Faculdade LatinoAmericana de Ciências Sociais (FLACSO) e graduado em filosofia pela Pontifícia Universidade Católica de Minas Gerais (PUC-MG). E-mail: ralasfer@gmail.com.
}

Sapere aude - Belo Horizonte, v. 7 - n. 14, p. 827-844, Jul./Dez. 2016 - ISSN: 2177-6342 


\section{NOT A BUG SPLAT}

"Father, if I killed your children with a drone bomb, How would you feel?" (Anohni)

"Nas neuroses de guerra, [...] o que se teme é, afinal, um inimigo interno" (Sigmund Freud)

Good kill $^{1}$ é o mais recente filme do diretor e roteirista Andrew Niccol. Esse trabalho produzido por Niccol é, talvez, a primeira película dramática especificamente sobre drones ${ }^{2}$. Tratase de um filme sobre a guerra e os seus efeitos em determinados indivíduos. O personagem principal, Tommy Egan, vive em Las Vegas e é um oficial da Força Aérea norte-americana. O que dá complexidade ao personagem é ele figurar dois momentos do que é compreendido como uma guerra, a guerra ainda heroica e a guerra que é apenas um assassinato via drones. Na primeira guerra existe a possibilidade de revide do seu inimigo em um campo de batalha e na segunda guerra é feita dentro de containers, em uma safe zone, e sem a possibilidade do confronto com o inimigo, ou seja, trata-se de extermínio. Não há mais heroísmo no que Tommy Egan faz e, por isso, agora ele se sente um "covarde" no seu trabalho. Egan trava uma guerra sem heroísmo, sem virtude. Este sentimento de covardia, a cada momento, vai se tornando mais complexo no desenvolvimento do filme.

O que Egan sente no trabalho reflete no âmbito familiar. Ao mesmo tempo em que os conflitos no trabalho vão se tornando mais intensos, a sua vontade de voar em combate é constantemente minada, e ele passa a se degradar cada vez mais. O personagem também perde a ilusão de voltar ao combate real, já que é ótimo como operador de drones e ele não é mais necessário como piloto. No espectro familiar há, também, um outro desgaste. Trata-se de Egan não somente estar a cada momento mais distante de sua família, mas a sua raiva contida por não poder voar é combinada com o constante uso do álcool. Neste momento já podemos ver que o drama de

\footnotetext{
1 "Good kill" é uma expressão para um bom tiro, um "tiro certeiro", na nossa expressão popular falamos de "um tiro na mosca". Contudo, a tradução para o português do título do filme ficou como "Morte limpa". No espanhol a tradução ficou como "Máxima precisión" e no alemão como "Tod aus der Luft" em diversas outras línguas não houve a tradução da expressão.

${ }^{2} \mathrm{O}$ nome "drone" ("zangão") é o que se popularizou para identificar o "veículo aéreo não tripulado" (unmanned aerial vehicle) ou ainda "veículo aéreo de combate não tripulado" (unmanned combat aerial vehicle). A distinção dos nomes se dá a respeito do uso ou não de uma arma na máquina.
}

Sapere aude - Belo Horizonte, v. 7 - n. 14, p. 827-844, Jul./Dez. 2016 - ISSN: 2177-6342 
Good kill é a respeito de um novo éthos militar, o que implicada em uma crise na compreensão do que é a guerra como, também, em uma possível psicopatologia do drone, como é entendida uma norma forma de subjetivação e os possíveis traumas de guerra de pilotos de drones em suas zonas seguras, em seus containers climatizados segurando o seu joystick fálico. Egan tem uma certa esquizofrenia, não no sentido clínico, mas ele fica nesta tensa divisão entre as 12 horas de trabalho em uma guerra contra o terrorismo e depois volta para casa por mais 12 horas para passar o tempo com seus amigos, com o seu filho e a sua bela esposa.

Na mídia é exposta de forma regular a insensibilidade dos operadores de drone. Até mesmo na música popular podemos encontrar críticas a estes pilotos, vale lembrar da canção "Coração Blindado" do grupo Engenheiros do Hawaii em que encontramos os seguintes versos: "moleza mandar a tropa atacar/na tela do computador/sem o cheiro/sem o som/sem ter nunca estado lá/sem ter que voltar pra ver o que restou/com a coragem que a distância dá/em outro tempo em outro lugar/fica mais fácil", ou ainda, Anohni na canção "Crisis" onde escutamos o seguinte "If I killed your father with a drone bomb how would you feel?". O drama de Egan é que ele teria compreendido que os corpos têm cheiro e que o barulho das bombas é ensurdecedor - o drone é este zangão da morte. Trata-se de ver rostos onde somente havia pontos. Todo o filme parece querer dar uma determinada dignidade aos pilotos de drones, posto que eles sofreriam os danos causados (mesmo que seja um sofrimento psíquico e não físico), trata-se do assassino de "guerra" que se compraz com sua vítima. Chamayou tem um precioso argumento sobre este tormento psíquico, pois é este desconforto psíquico que ainda o tornaria soldado. O soldado seria definido por poder ser tanto a vítima como o algoz, mas o piloto de drone é apenas o algoz solitário dentro de uma cabine com ar condicionado, torna-se necessário evocar o tormento psíquico, pois, desta forma, ele seria uma vítima psíquica de ter agido como algoz.

A campanha "not a bug splat"3 por um grupo de artistas-ativistas que atendem pelo nome de Inside Out Projet foi uma das várias empreitadas na tentativa de criar uma consciência nos pilotos de drones, dar um rosto ao que eles estão assassinando. Pois, não se trata de jogar Play Station ou Xbox como os primeiros pilotos de drones diziam em suas entrevistas para a grande

\footnotetext{
${ }^{3}$ Os operados de drones na gíria militar quando matam determinado alvo fazem referência a estes mortos como "bug splat" que poderíamos traduzir por algo como "inseto esmagado". A campanha, por sua vez, joga com este termo dizendo que não se trata de um inseto esmagado, mas encontramos ali um rosto. Uma tradução livre para "not a bug splat" poderia ser "sem inseto esmagado".
}

Sapere aude - Belo Horizonte, v. 7 - n. 14, p. 827-844, Jul./Dez. 2016 - ISSN: 2177-6342 
mídia. No final das contas encontra-se ali uma vida com um rosto e não apenas um ponto ou ainda um inseto. Coloco duas imagens da campanha "not a bug splat" para a compreensão do impacto que ela poderia causar. Nesta primeira imagem ${ }^{4}$ vemos como aparecem os indivíduos em uma câmera de um drone tradicional.

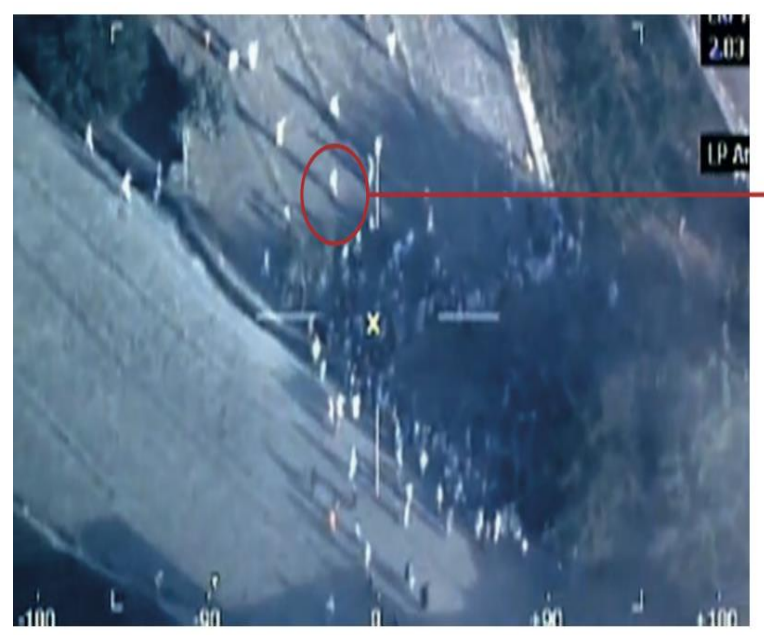

Humans appear as disposable bugs when viewed through a traditional drone camera.

We changed this.

Now, a drone will see an actual face of a child, creating dialogue and, possibly, empathy.

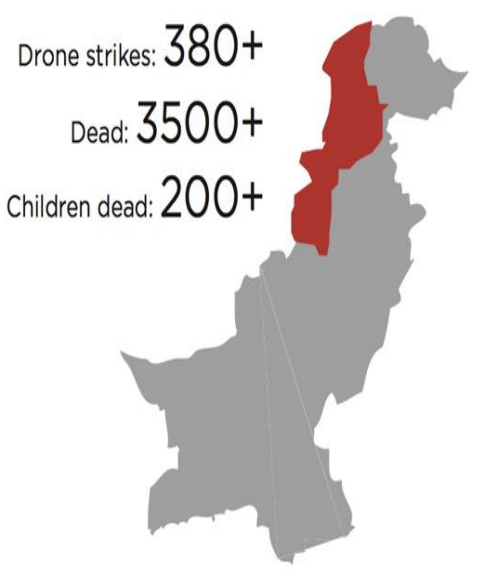

Figura I. Como as pessoas são vistas por uma câmera de drone tradicional.

O que a campanha "not a bug splat" faz é colocar a face de uma criança onde o operador do drone iria ver somente pontos, assim, tendo a esperança que isso gerasse uma possível empatia, ou ainda, que ao ver a face de uma criança como alvo estes operadores de drones fossem, de alguma forma, humanizados. A imagem que eles iriam ver é a que segue abaixo.

\footnotetext{
${ }^{4}$ As duas figuras foram retiradas do site http://notabugsplat.com/ onde é possível encontrar mais informações sobre a instalação que podemos ver na segunda figura.
}

Sapere aude - Belo Horizonte, v. 7 - n. 14, p. 827-844, Jul./Dez. 2016 - ISSN: 2177-6342 


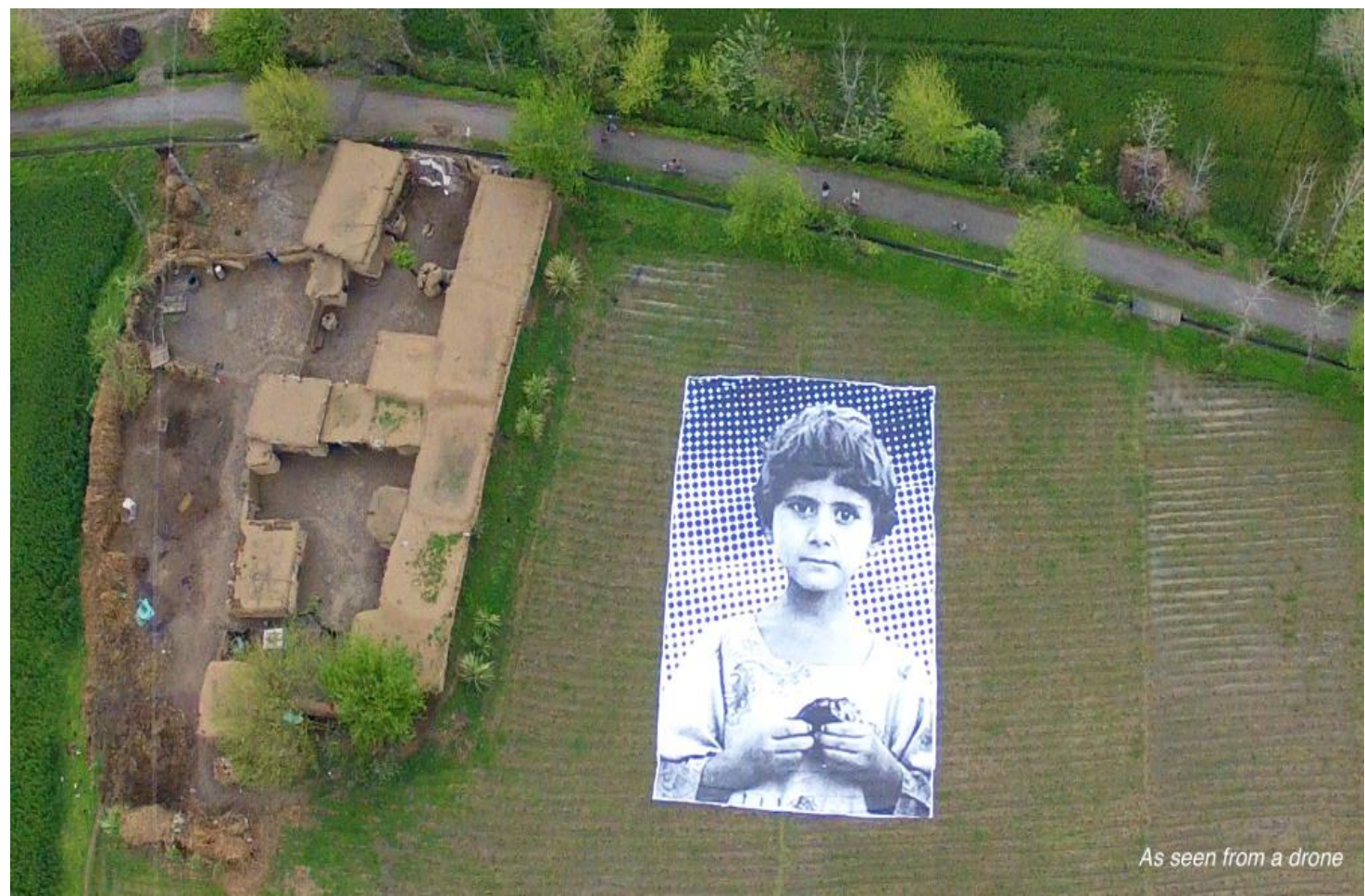

Figura II. O operador do drone não mais veria somente um inseto a ser morto, mas a face duma criança.

Creio que com estes primeiros elementos expostos é possível, agora, voltarmo-nos para um desenvolvimento filosófico a respeito da questão da vigilância, para que depois regressemos ao filme para abordarmos não somente aspectos da vigilância via drone, mas, além disso, saber como as novas tecnologias de guerra afetam o indivíduo em meio a um novo éthos militar, a uma nova maneira de conceber a guerra. E claro que temos como exemplo o filme Good Kill e os conflitos éticos de Tommy Egan.

\section{MICHEL FOUCAULT E A TOUPEIRA DIVINA}

"O panóptico é uma máquina de produzir uma imitação de Deus" (Jacques-Alain Miller)

Michel Foucault em seu livro Vigiar e Punir faz uma genealogia do indivíduo moderno enquanto sujeito. Tem-se neste livro, também, uma análise das sociedades disciplinares e ensejos 
para o que o filósofo, Gilles Deleuze, depois veio a chamar de sociedade de controle. Na obra Vigiar e Punir encontramos a análise de um ambiente cinza, são as fábricas, os hospitais, os hospícios, as escolas etc., Foucault compreendeu que a sociedade disciplinar era formada por estes arquipélagos carcerários, ou ainda, para utilizarmos uma imagem deleuziana, estes ambientes são uma variedade de buracos de toupeiras. Nestes lugares fechados encontramos o que Foucault vai denominar como disciplina e, além disso, todo um processo de docilização dos corpos. É uma nova forma de poder que é operada no sujeito, um micropoder que vai adentrar nos detalhes, em cada parte do indivíduo. Do corpo dócil não mais somente uma submissão, mas, também, todo um aperfeiçoamento e a produção de uma utilidade. Os corpos dóceis são adestrados. Todavia, o que nos interessa neste momento não é salientar de forma monótona as diversas formas de um bom adestramento, mas, remontarmo-nos ao sonho do filósofo e jurista, Jeremy Bentham, de uma arquitetura que poderia produzir uma total vigilância, o que o autor deu o nome de Panóptico.

O panóptico que pode ser definido, levando em conta a etimologia da palavra, como um “olho que tudo vê", ele é um projeto arquitetônico, primeiramente, pensado para uma prisão. Neste projeto haveria uma torre central que poderia ver os presos em cada uma de suas celas, porém os presos não veriam quem poderia estar vigiando-os. Deste modo, geraria um sentimento de constante vigilância, de uma vigilância ininterrupta. Se quando havia os presos nas antigas masmorras o intuito era trancar, privar de luz e visibilidade, agora, com o panoptismo a ideia é trancar, dar luz e gerar visibilidade, sendo que "a visibilidade é uma armadilha" (Foucault, 2009, p. 190). A visibilidade é uma armadilha, posto que quanto maior o campo de visibilidade do prisioneiro, maior seria o saber e o poder sobre aquele corpo. Abaixo encontramos um exemplo de um desenho arquitetônico de forma panóptica feita pelo arquiteto Willey Reveley:

Sapere aude - Belo Horizonte, v. 7 - n. 14, p. 827-844, Jul./Dez. 2016 - ISSN: 2177-6342 


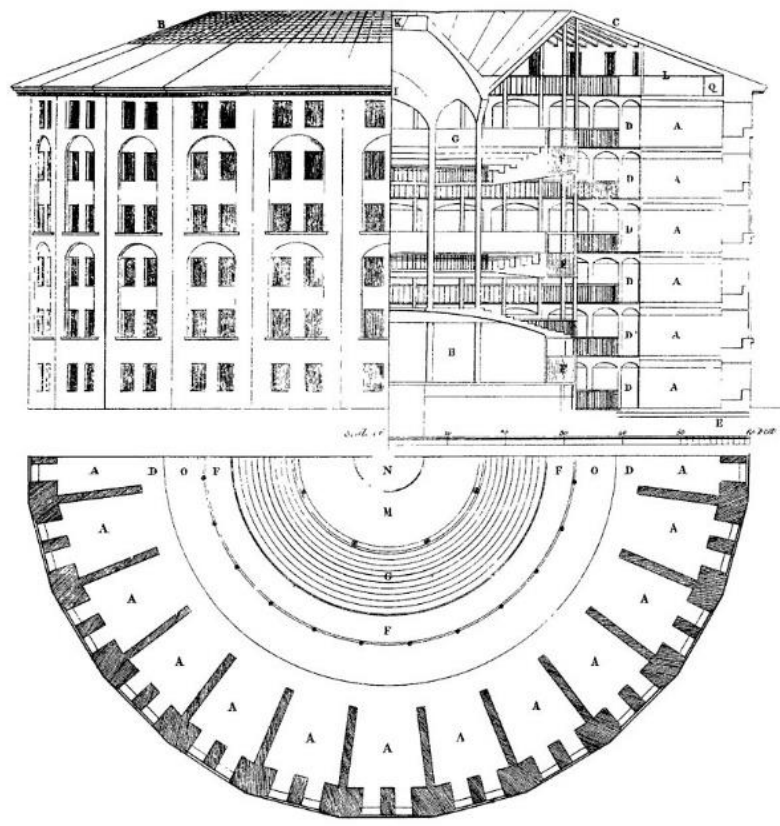

Figura III: Projeto arquitetônico de forma panóptica do arquiteto Willey Reveley.

Não obstante ao que encontramos nesta figura é necessário afirmar que o panoptismo não é somente uma estrutura física, mas uma tecnologia de poder, um dispositivo de vigilância que induz a um estado de permanente de visibilidade. Desta forma, o panoptismo entendido como uma tecnologia ele poderia colonizar outros ambientes, ele poderia ser aplicado a outros lugares que não seja a prisão. O panoptismo como um princípio é ramificável e flexível e esta compreensão do panóptico já encontramos nas cartas de Bentham (carta 19, 20 e 21), ou seja, a mesma estrutura panóptica (o princípio da inspeção) poderia ser utilizado em diversos outros âmbitos.

Jacques-Alain Miller (2008) aponta que os dois princípios fundamentais da construção panóptica são "posição central da vigilância e sua invisibilidade" (p.90), dois pontos que podemos ver na terceira figura. A respeito do primeiro ponto a posição circular é a mais econômica, economia com relação ao pessoal, pois com a arquitetura central é possível utilizar somente um inspetor. A respeito do segundo ponto aí se mostra a característica mais astuciosa do dispositivo de vigilância que é ver sem ser visto. E neste sentido o panóptico é a imitação de Deus, o olhar do inspetor (existente ou não) tem uma aparente onipresença. Se seguirmos os passos não só de Foucault, mas dá análise de Miller chegamos à conclusão que este Olhar é uma imitação de Deus,

Sapere aude - Belo Horizonte, v. 7 - n. 14, p. 827-844, Jul./Dez. 2016 - ISSN: 2177-6342 
a produção de um Deus artificial, todavia, deveríamos acrescentar que este Deus, talvez, não seja nem bom nem justo (ao menos para os insurgentes), mas compõe toda a mitologia da disciplina e do controle.

\section{GILLES DELEUZE E OS ANÉIS DA SERPENTE}

"Os anéis de uma serpente são ainda mais complicados que os buracos de uma toupeira"

(Gilles Deleuze)

Gilles Deleuze em 1987, em uma palestra sobre o ato de criação, já começa a desenvolver a ideia de uma sociedade de controle, mas é em um pequeno texto de 1990 intitulado Post-scriptum sobre as sociedades de controle que encontramos o tema elaborado de forma mais precisa. Encontramos, novamente, a questão do controle numa entrevista com o filósofo italiano Toni Negri, mas não há um acréscimo considerável ao que foi desenvolvido anteriormente. Deleuze aponta que Foucault ao analisar as sociedades disciplinares, já havia compreendido que esta sociedade é a que estamos deixando para trás, estamos entrando na sociedade do controle. Não mais a toupeira e o seu confinamento, a toupeira e seu espaço moldado, mas a serpente ao ar livre com o seu rastejar ondulatório, sua modulação corporal.

Por mais que Deleuze aponte que todos os ambientes disciplinares estão em crise, a família, a escola, a prisão, os hospitais etc., creio que estaríamos in medio a estas duas sociedades. Estaríamos junto ao "resto" de uma gama de rudimento disciplinares, assim creio que seja possível vermos elementos da sociedade disciplinar e da sociedade de controle, vermos a toupeira foucaultiana e a serpente deleuziana. Este estado de estar no meio de talvez continue por um bom tempo, posto que várias instituições, tipicamente disciplinares, parecem endurecer mais a disciplina do que desenvolver o controle como, por exemplo, as prisões que ficam cada vez mais cheias e duras. Daí que se torna necessário fazermos uma distinção conceitual destas duas formas de sociedades, não só para um aclaramento teórico, mas para uma real compreensão do que é e pode vir a ser o controle.

As sociedades de controle podem ser situadas em um período que percorreria o século XVIII até a Segunda Guerra Mundial, sendo que os anos da segunda metade do século XX estaria

Sapere aude - Belo Horizonte, v. 7 - n. 14, p. 827-844, Jul./Dez. 2016 - ISSN: 2177-6342 
marcado pela ascensão do controle. Não mais haveria somente a disciplina nos lugares fechados, agora encontraríamos o controle a céu aberto. Deleuze no seu Post-scriptum..., nos dá a imagem de uma rodovia para a distinção da disciplina com relação ao controle. Uma rodovia, uma autoestrada é uma imagem apropriada, porque nos evoca a imagem de dirigir um carro velozmente, de estar a céu aberto. Todavia, para Deleuze as pessoas rodariam "livremente" e estariam perfeitamente controladas. Poderíamos acrescentar outros lugares de um contínuo controle como, por exemplo, a rua, as praças e, em geral, a maioria dos ambientes públicos são equipados por equipamentos de vigilância. Entretanto, para além destas imagens existe uma variedade de elementos que distingue a sociedade disciplinar da sociedade de controle; para o nosso intuito o dado principal é que a primeira funciona por moldes e a segunda por modulações e, desta distinção que colocamos aqui como primária, segue-se outras informações importantes para a nossa análise diferencial.

Deleuze compreende os confinamentos da sociedade disciplinar como moldes, as moldagens exigem um modelo fixo que poderia ser aplicado às diversas formas sociais. A sociedade de controle, por sua vez, é marcada pela modulação, pela onda, pela imagem do surf, pois não há um limite definido. Na primeira sociedade o indivíduo estaria em uma quitação aparente e na segunda sociedade na moratória ilimitada, ou seja, no primeiro caso o indivíduo estaria sempre quitando a sua dívida entre várias estruturas de confinamento e no segundo caso a dívida seria impagável, posto que o indivíduo estaria sempre enredado em uma espécie de formação permanente, o indivíduo teria que estar sempre se modulando. Deleuze afirma que: "nas sociedades de disciplina não se parava de recomeçar (da escola, da caserna à fábrica), enquanto nas sociedades de controle nunca se termina nada, a empresa, a formação, o serviço sendo os estados metaestáveis e coexistentes de uma mesma modulação, como que de um deformador universal" (Deleuze, 2013, pp. 225-226).

Outro elemento que decorre da distinção feita entre o molde e a modulação é que na sociedade disciplinar os indivíduos seriam de fato indivisíveis (a marca central é a assinatura e a matricula) e na sociedade de controle eles seriam divisíveis (a marca central é a cifra, a senha). A assinatura indicaria um indivíduo e sua matricula a posição na massa, tem-se o par massaindivíduo. Na sociedade de controle a cifra é uma senha que marca o acesso ou não a informação. Os indivíduos são agora “dividuais”, porque o código intransferível marca o seu lugar e o não- 
lugar. As massas, por sua vez, tornam-se amostras, dados, mercados etc., e tais dados têm que ser analisados, rastreados para que possam ser compreendidos à Minority Report. Daí podemos ver a forma do pensamento de Deleuze que antevê toda uma gama de tecnologia que tem o indivíduo como cifra, como código digital dentro de uma variedade de amostras, esta sofisticação do molde para os indivíduos dividuais é o que mais caracteriza a sociedade de controle não só em 1990, mas também, na atualidade hiperconectada, interconectada e reticular. Rogério da Costa em um artigo chamado "Sociedade de controle" afirma que:

Nenhuma forma de poder parece tão sofisticada quanto aquela que regula os elementos imateriais de uma sociedade: informação, conhecimento, comunicação. $\mathrm{O}$ estado, que era como um grande parasita nas sociedades disciplinares, extraindo mais valia das atividades dos indivíduos, hoje está se tornando uma verdadeira matriz onipresente, modulando continuamente os fluxos desses mesmos indivíduos, segundo variáveis cada vez mais complexas. Na sociedade de controle, estaríamos passando das estratégias de interceptação de mensagens ao rastreamento de padrões de comportamento (Costa, 2004, p.35. Itálico nosso).

Não mais somente a interceptação da informação, a interceptação de uma mensagem; o rastreamento de padrões de comportamento, todavia. Trata-se de criar um Perfil do usuário por meio de padrões de procedimentos.

No filme Good Kill é possível ver esta mudança de forma clara na cena em que a equipe em que Egan trabalha passa a receber ordens da CIA. Neste momento o Coronel diz que: "agora vamos atuar, com o que eles chamam ataque de assinatura. E o que isso quer dizer é que atacamos não pelo alvo, mas pelo comportamento. Ou seja, vocês podem ser mandados disparar sobre qualquer idiota com uma AK47. Apesar de nós sabermos que toda a gente, até as mães andam com $A K 47$ ”. Importante notar que há dois tipos de ataques, os "ataques de personalidade" nominativos e os "ataques de assinatura". Os ataques por assinatura se parecem mais com a cifra deleuziana, o código e suas relações. Com esta fala podemos entender a modulação deleuziana, pois a informação não está em um indivíduo, mas nas conexões, nas relações que este sujeito faz, no horário em que ele sai de casa, nas vielas ou nas ruas em que ele anda, no alimento que ele come, nas viagens que ele faz e, também, na possível arma que ele segura. Estes dados são relacionados entre si, estes dados são modulações do indivíduo dividual. No primeiro caso, no ataque nominal, se sabe qual indivíduo vai ser eliminado, e no segundo caso, ataca-se sem conhecer a identidade do indivíduo,

Sapere aude - Belo Horizonte, v. 7 - n. 14, p. 827-844, Jul./Dez. 2016 - ISSN: 2177-6342 
posto que já se conhece o comportamento dele e por meio daquela conduta aos lugares que ele pertence.

Ainda é possível lembrar do filósofo, Didier Bigo, que tem uma pesquisa interessante em torno do conceito de banoptismo. A ideia é que se cria um perfil e então determina a mobilidade de determinados sujeitos, trata-se de banir (sistema banóptico) e depois vigiar (sistema panóptico), porém, quando os drones entram em jogo, a questão não é vigiar e punir, nem vigiar e banir, mas sim: vigiar e aniquilar.

\section{A VIGILÂNCIA GEOESPACIAL E OS PRINCÍPIOS DO DRONE}

"Até os cabelos da cabeça de vocês estão todos contados"

Antes de nos atermos a Grégoire Chamayou e sua Teoria do Drone, convém remontarmos novamente a mitologia da disciplina e do controle. A figura arquetípica de um Deus que poderia ver tudo é a representação da ideia de um controle social absoluto. Deus no Novo Testamento e no Corão é aquele que tudo vê, todo sabe e tudo pode, assim, o que temos no controle social é a tentativa de produção de um olhar divino e artificializado por meio de uma produção tecnológica. Tomemos, por exemplo, a pintura de Jan Provost (Figura IV) intitulada Alegoria Sacra, nela podemos ver o olho de Deus com o Seu poder onividente, o Seu olhar que percorre todos os detalhes, é o olhar de um Deus (que como na epigrafe primeira do nosso texto) que sabe cada fio de cabelo que nós temos.

Sapere aude - Belo Horizonte, v. 7 - n. 14, p. 827-844, Jul./Dez. 2016 - ISSN: 2177-6342 


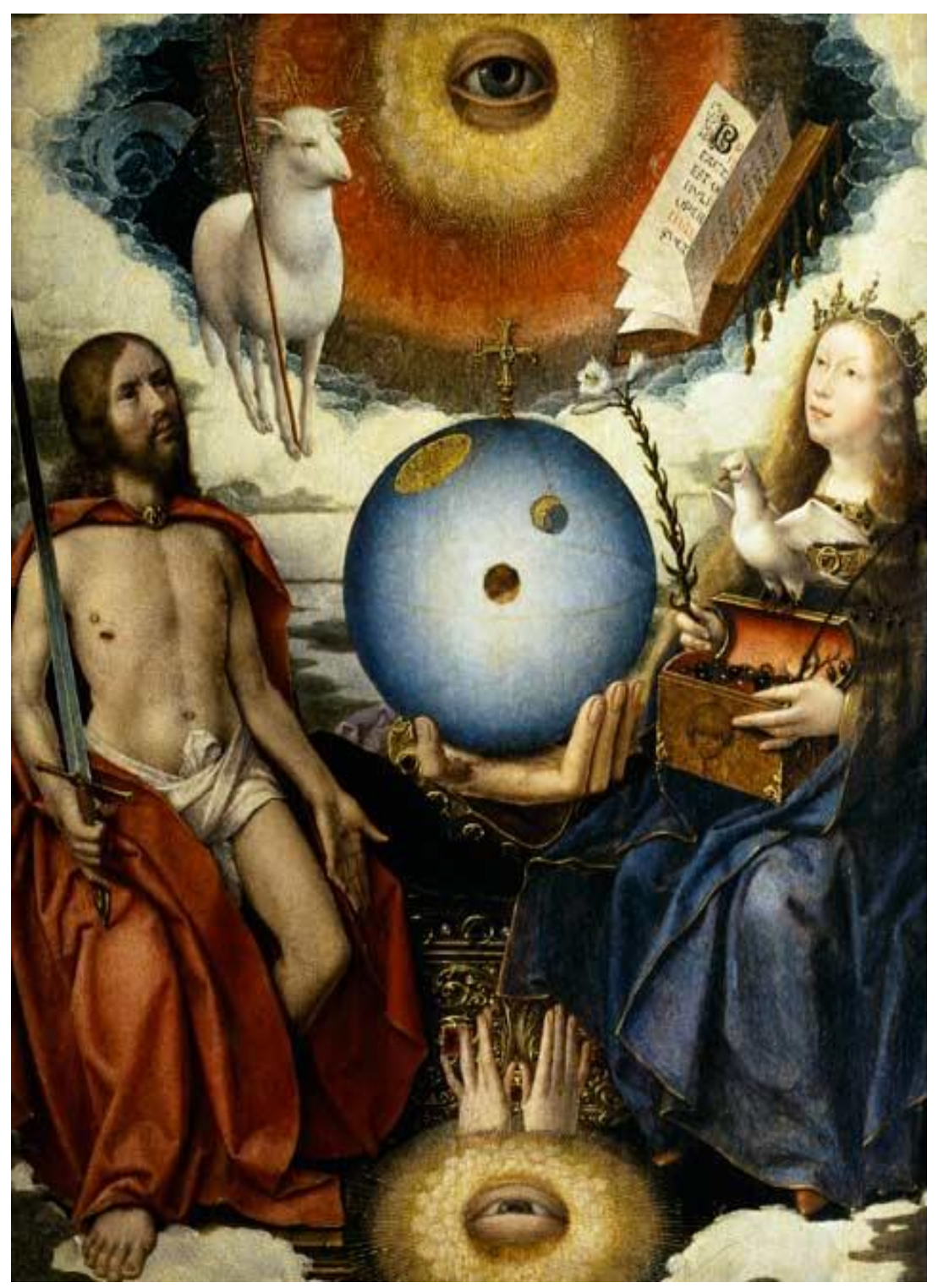

Figura IV: Alegoria Sacra (1510-1520) de Jan Provost.

Chamayou afirma que "em muitos aspectos, o drone sonha realizar, pela tecnologia, um pequeno equivalente dessa ficção do olho de Deus" (Chamayou, 2015, p. 47), os drones teriam provocado uma revolução no olhar. O autor de Teoria do Drone elenca seis princípios que sintetizam esta revolução no olhar. Abordamos aqui alguns destes princípios de uma forma distinta da ordem proposta pela Teoria do Drone para, desta forma, selecionarmos o que é mais importante para a nossa análise que vária entre a vigilância, o conflito ético e uma possível psicopatologia do drone. Assim sendo, seguimos com quatro princípios: 
i) Princípio da vigília permanente. O princípio da vigília permanente representa um contraponto ao olhar humano, o olhar que em algum momento vai piscar e perder um segundo da vigilância. $\mathrm{O}$ olhar do drone, por sua vez, não tem pálpebras e a vigilância é permanente e constante. Tem-se uma vigilância geoespacial ininterrupta.

ii) Princípio do filme de todas as vidas. A vigilância não é limitada a vigília em tempo real, mas juntamente a vigília encontramos a gravação e o arquivamento. Trata-se de criar um filme de todas as vidas vigiadas, onde é possível rever fatos, perpassar outros trechos, focar outros elementos. Com a gravação e o arquivamento seria possível encontrar as gêneses, ou seja, se uma cidade fosse vigiada de uma só vez, algum possível terrorista poderia ser encontrado em seu ponto de origem. Para citarmos outro filme de Andrew Niccol poderíamos mencionar o belo Show de Truman, e toda a sua vida sendo gravada e vigiada, aliás, transformada em reality show.

iii) Princípio de esquematização das formas de vida. O princípio da esquematização das formas de vida ("pattern of life") para Chamayou constituiria "um dos principais suportes epistêmicos da vigilância armada". Neste princípio temos o que chamamos anteriormente de criação de um Perfil, entendendo-o como a vigilância do indivíduo nas redes sociais a fim de estabelecer o esquema de vida com base no comportamento, na conduta do sujeito. Neste momento o importante não é identificar uma identidade nominal, mas reconhecer anomalias, qualificar pela tipicidade de um comportamento de uma identidade genérica.

iv) Princípio de detecção das anomalias e da antecipação preventiva. Esse princípio envolve, primeiramente, a procura de uma anomalia no comportamento padrão de indivíduos e, depois, segue a prognóstico de possíveis desenvolvimentos. Sobre este segundo elemento Chamayou afirma que "os arquivos das vidas formam a base sobre a qual, por meio da identificação das regularidades e antecipações das recorrências, se pretende conseguir de uma só vez predizer o futuro e modificar o seu curso por uma ação preemptiva" (Chamayou, 2015, pp. 53-54). O princípio da antecipação preventiva nos remonta, na experiência cinematográfica, ao filme Minority Report e, a constante, predições de crimes. Claro que como no filme o drama é que estas predições podem em algum momento falhar.

Sapere aude - Belo Horizonte, v. 7 - n. 14, p. 827-844, Jul./Dez. 2016 - ISSN: 2177-6342 
Com esses dados nos encontramos diante de variações sobre a disciplina e o controle, variações a respeito do olho que tudo vê, variações sobre as diversas formas de panoptismo. Com o panóptico de Jeremy Bentham estamos ainda muito vinculados aos planos arquitetônicos (com Foucault aprendemos que não há projeto arquitetônico ingênuo), e ao que Foucault chamou de ambiente disciplinar, os arquipélagos carcerários. Quando pensamos em Deleuze (e possíveis leituras por meio do seu pensamento) a questão da vigilância se transmuta para um controle reticular, a vigilância é a céu aberto com suas câmeras de videovigilância. Todavia, quando chegamos na vigilância via drone, a vigilância geoespacial, "as câmeras se desprendem dos muros e nelas crescem asas e armas" (Chamayou, 2015, p. 54). Desta forma, pensando em uma brevíssima filmografia para relacionar estas diferentes configurações teóricas com uma diversidade de filmes, poderíamos salientar alguns filmes chave como o panóptico de Bentham na leitura de Foucault com a película $O$ ovo da serpente, de Ingmar Bergman. A videovigilância deleuziana com o filme Controle absoluto e Paranoia, ambos de D.J Caruso. E os drones tal como analisados por Chamayou com a película Good kill.

\section{GOOD KILL E A PSICOPATOLOGIA DO DRONE}

"Não são pilotos de avião, mas operadores de drone, de joysticks. A doutrina do presidente Obama está inteiramente embutida nessa nova tecnologia: matar, não capturar. Não a tortura, como em Guantánamo, mas o assassinato seletivo"

(Peter Pál Pelbart) 


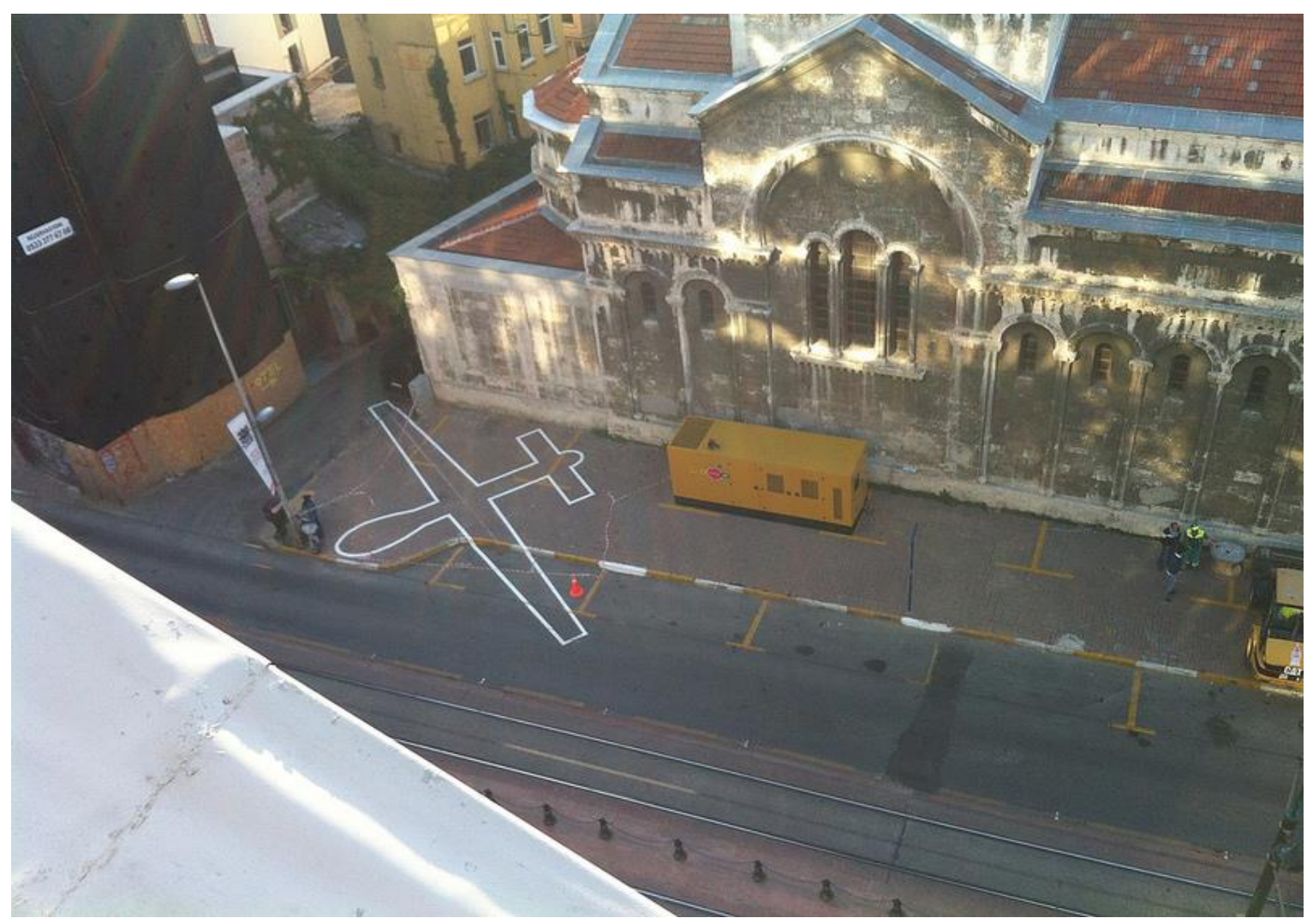

Figura V: Sombra de um Drone, de James Bridle.

Já havíamos apontado que o drama de Tommy Egan é que ele foi um piloto em combate, ou seja, participou de um éthos clássico militar; Egan depois começou a pilotar os drones, entretanto. Em um momento chave do filme ele afirma que sente saudades de sentir o medo e que trabalhando com os drones o máximo que pode acontecer ao corpo dele é que um copo de café caia nas suas pernas e o queime, ou ele ficar com alguma lesão na mão por esforço repetitivo. Ele perde tudo que envolvia o éthos militar clássico que seria ter algumas virtudes como coragem, sacrifício, heroísmo..., a tristeza lacônica de Egan parece ser a de quem faz o luto deste éthos militar, todavia o que ele encontra pilotando drone é uma guerra sem virtude, uma guerra pós-heroica e toda a perde duma virilidade militar.

Chamayou acerca desta virilidade nos lembra como seria difícil traduzir a primeira palavra de unmanned aerial vehicle. A palavra "unmanned” seria quase intraduzível, ela tem o seu lastro etimológico na palavra “man” ("homem”), assim sendo, a sua tradução literal seria algo como "des-homenado", mas temos quatro palavrinhas mais próximas para dizer do que se trata este 
“unmanned" e elas são: 1) falta de coragem, 2) des-virilidade, 3) castração, 4) e emasculação. O personagem Tommy Egan sente na pele a sua desvirilidade, basta lembrar que em determinada cena Egan evita o sexo com sua esposa e, em outra cena ele se envolve, mas não está conectado com ela.

No caso de Egan, ele perde a sua virilidade ao pilotar os drones e antevê de alguma forma que, talvez, haja algum heroísmo em lutar pela pátria, mas não eliminar, assassinar via uma lógica comportamental de vigilância que é, também, um dispositivo de biopolítica do controle, uma biopolítica racista em que a alteridade é eliminada em prol dos valores da sociedade ocidental na qual determinados comportamento são erradicados via extermínio. No entanto, o filme parece terminar de forma ambígua, pois se por um lado Egan ao final do filme ele deixa de trabalhar com os drones (desvinculando da lógica militar), por outro lado, o filme mostra a todo tempo Egan atormentado por assassinar alguns terroristas e uma gama enorme de civis. Este tormento psíquico pode ser compreendido, novamente venho frisar este ponto, como uma legitimação dos pilotos de drone, por meio do sofrimento psíquico se dá um verniz de humanidade ao assassinato, seria apontar que eles teriam uma vulnerabilidade física, assim, de alguma forma seriam mais de que uma mentalidade Play Station, mas, também, soldados, já que estão vulneráveis aos efeitos psíquicos da guerra. Do sacrífico físico (o militarismo clássico) se passa ao sacrífico psíquico (do militarismo via drone). Entretanto, Chamayou nos mostra que não há indícios para uma psicopatologia dos drones, para um real trauma destes pilotos, o que eles sentem não é um tormento por exterminar pessoas, mas são têm outros sofrimentos e outras demandas com relação ao seu trabalho.

A tentativa de humanização de Good Kill está no fato de Tommy Egan se mostrar o tempo todo silenciosamente atormentado por seu trabalho. O que gera o drama é pensar que em um minuto se está fazendo a guerra contra o terrorismo e matando pessoas e depois encontramos Egan voltando para casa no seu carro para fazer um churrasco com os amigos, ensinar o filho matemática etc., Egan, desta forma, vive em dois mundos. Daí que começou a se falar dos tormentos dos pilotos de drone e, principalmente, do estresse pós-traumático ("Post-traumatic Stress Disorder-PTSD). A este estresse pós-traumático dos pilotos de drone Chamayou nos lembra de uma boa imagem " $a$ do crocodilo, que só derrama lágrima para melhor devorar sua presa" (Chamayou, 2015, p. 124. Itálico nosso). Nas pesquisas de Chamayou ele não encontrou uma psicopatologia do drone, não

Sapere aude - Belo Horizonte, v. 7 - n. 14, p. 827-844, Jul./Dez. 2016 - ISSN: 2177-6342 
encontrou pessoas com traumas psíquicos como o estresse pós-traumático elaborado no Manual Diagnóstico e Estatístico de Transtornos mentais ("Diagnostic and Statistical Manuel of Mental disorders” - DSM). Claro que sabemos que há uma produção distinta de uma subjetividade dos pilotos de drone, mas salientemos aqui que o estresse pós-traumático para os pilotos de drone é uma impossibilidade lógica, já que para haver tal estresse eles teriam que estar expostos a um evento ameaçador real que incluiria a morte, uma ameaça à integridade física do sujeito. Percebemos logo a incoerência de uma classificação dos operadores de drone nesta nosógrafa; novamente, é necessário afirmar que eles de forma alguma sofrem uma ameaça física, mas, sim, eles são os causadores de uma degradação física, da morte do outro. Além disso, Chamayou salienta que o verdadeiro problema dos operadores do drones não seria o estresse pós-traumático, mas eles são afetados por distúrbios do sono e outros elementos que poderíamos vincular a trabalhos monótonos e estressantes. O problema para os operadores de drones não seria uma questão ética, mas pragmática: como ter um copo com uma tampa que não deixaria pingar café arábica nas minhas pernas?

\section{REFERÊNCIAS}

BENTHAM, Jeremy. O panóptico. Belo Horizonte: autêntica, 2008.

BIGO, Didier; TSOUKALA, Anastassia. Terror, insecurity and liberty. New York/Canada, 2008.

CASTELO BRANCO, Guilherme. Michel Foucault: filosofia e biopolítica. Belo horizonte: autêntica, 2015.

CHAMAYOU, Gregoire. Teoria do drone. Trad. Célia Euvaldo. São Paulo: Naify, 2015.

DELEUZE, Gilles. Conversações. São Paulo: ed. 34, 1992.

FOUCAULT, Michel. Vigiar e punir: história da violência nas prisões. Rio de Janeiro: Vozes, 2009.

LEMOS, Flávia Cristina Silveira et al . A guerra atual e o uso de drones: práticas biopolíticas do matar em nome da vida. Rev. psicologia política. São Paulo. v. 14. n. 30. p. 283-

295. Agosto. 2014.Disponívelem: $<$ http://pepsic.bvsalud.org/scielo.php?script=sci_arttext\&pid=S 1519-549X2014000200005\&lng=pt\&nrm=iso.> Acessos em 03 abr. 2016.

Sapere aude - Belo Horizonte, v. 7 - n. 14, p. 827-844, Jul./Dez. 2016 - ISSN: 2177-6342 
LEOPOLDO, Rafael. Deleuze \& Guattari: critica a psicanálise freudiana. Dissertação de mestrado. Programa de Pós-graduação em Psicologia da Universidade Federal de Juiz de Fora, 2015.

LEOPOLDO, Rafael. Vigilância líquida: variações sobre o panoptismo. Sapere Aude - Revista de Filosofia, Belo Horizonte, v. 6, n. 12, p. 894-902, jan. 2016. Disponível em:

<http://periodicos.pucminas.br/index.php/SapereAude/article/view/11261>. Acesso em: 03 Abr. 2016.

PELBART, Peter Pál. A terra, a guerra, a insurreição. Revista ECO-Pós, [S.1.], v. 18, n. 2, p. 161-170, out. 2015. Disponível em:

<https://revistas.ufrj.br/index.php/eco_pos/article/view/2665>. Acesso em: 03 Abr. 2016. 